\title{
Traumatic spinal epidural hematoma: A case review
}

\author{
Lydia Prusty $^{1}$ and G. K. Prusty ${ }^{2 *}$ \\ ${ }^{1}$ Department of General Surgery, M.G.M. Medical College, Kishanganj, Bihar, India. \\ ${ }^{2}$ M.G.M. Medical College, Kishanganj, Bihar, India.
}

Accepted 9 March, 2017

\begin{abstract}
There are very few cases of post traumatic Spinal Epidural Hematoma (SEH) reported in literature. The authors have reported five such cases of SEH who have all had a history of trauma. All five cases underwent early surgical intervention and four of them recovered completely while one recovered with some post-operative neurological deficit. SEH must be considered when there is a history of trauma to spine to avoid unnecessary delay in initiating appropriate treatment.
\end{abstract}

Keywords: Trauma, spinal epidural hematoma, cervical spine, thoracic spine.

*Corresponding author. E-mail: drgkprusty@gmail.com.

\section{INTRODUCTION}

Spinal Epidural Hematoma (SEH) is a rare and potentially life threatening condition. Traumatic SEH is even more uncommon and accounts for a very small percentage of all cases of SEH with only about ten cases reported in literature so far (Cha et al., 2011).

$\mathrm{SEH}$ is an uncommon condition first described in the 17th Century (Lefranc et al., 1999). Most of these cases are thought to occur spontaneously and associated with coagulopathy, vascular malformation, neoplasms, minor trauma and pregnancy. Traumatic SEH with neurological deficit is very uncommon (Cha et al., 2011; Lefranc et al., 1999; Krishnan and Kartikueyan, 2014).

The authors reported five cases seen over a period of 9 years. All cases were operated by single surgeon. These cases of SEH are unique because of their association with blunt trauma with no other associated injuries and complete resolution of symptoms after surgical management except in one case where the patient was left with some neurological deficit.

\section{CASE REPORT}

\section{Case 1}

A 64 year old female patient had slipped and fallen down in the bathroom. She sustained a blunt injury to the nape of her neck. She managed to get up herself but continued to get pain in the region of the injury. Next morning, about 22 hours after the incident, she was unable to get out of bed as she was experiencing weakness of all four limbs and numbness in her entire body. She could pass urine normally. When clinically evaluated, it revealed local bruise in the back in the lower part of neck. Neck movement was normal. She had grade IV weakness of all extremities. Deep Tendon Reflexes were normal. However, extensor plantar reflex was noted. There was no definite sensory level. Vitals were normal. X-Ray cervical spine was normal and not suggestive of any pathology. MRI done as a routine emergency procedure revealed Cervical SEH extending from $\mathrm{C} 3-\mathrm{C} 7$ along with cord compression in the corresponding area (Figures 1 and 2). Patient underwent emergency laminectomy of C3-C6 with evacuation. Intra-operatively, no vascular lesion could be seen in the epidural space. Laminoplasty was done. Post operatively, patient improved steadily and at $10^{\text {th }}$ week, she recovered completely with no neurological deficit.

\section{Case 2}

Our next case is a 63 year old female patient who is on regular medication for diabetes and hypothyroidism. She sustained an injury due to an accidental fall from stairs. She received direct blunt injury to her back. She 


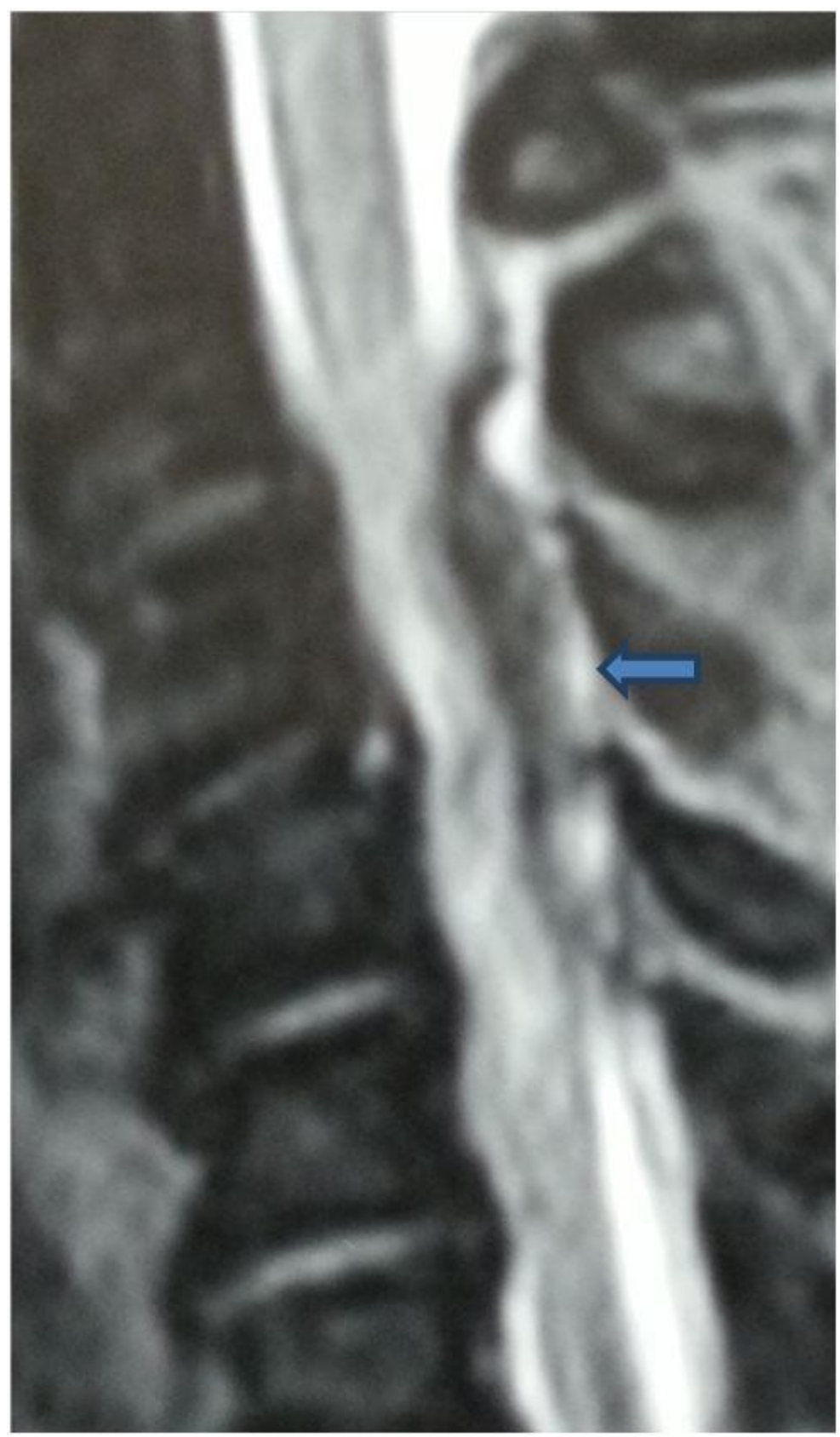

Figure 1. MRI (gradient echo) showing cervical EDH posterior to cord.

complained of local pain which was initially alleviated with use of Paracetamol and local application of Volini Gel. About 46 hours later, she developed weakness of both legs along with retention of urine. When clinically examined, it revealed a distended palpable bladder with paraparesis 4/5, normal Deep tendon reflexes, and sensory blunting below D-10 level for fine touch only. There was a large bruise on the back over the dorsal region with local tenderness. Her X-Ray dorsal spine did not reveal any abnormality. However MRI revealed a large epidural hematoma (Figures 3 and 4).
Patient underwent emergency laminectomy along with removal of the hematoma. Post operative period was uneventful. Patient recovered completely in her neurological status in 14 weeks.

\section{Case 3}

A 38 year old male exercising in gym had a sudden catch in the mid dorsal spinal region which was followed by excruciating pain. Thereafter he drove back home for 


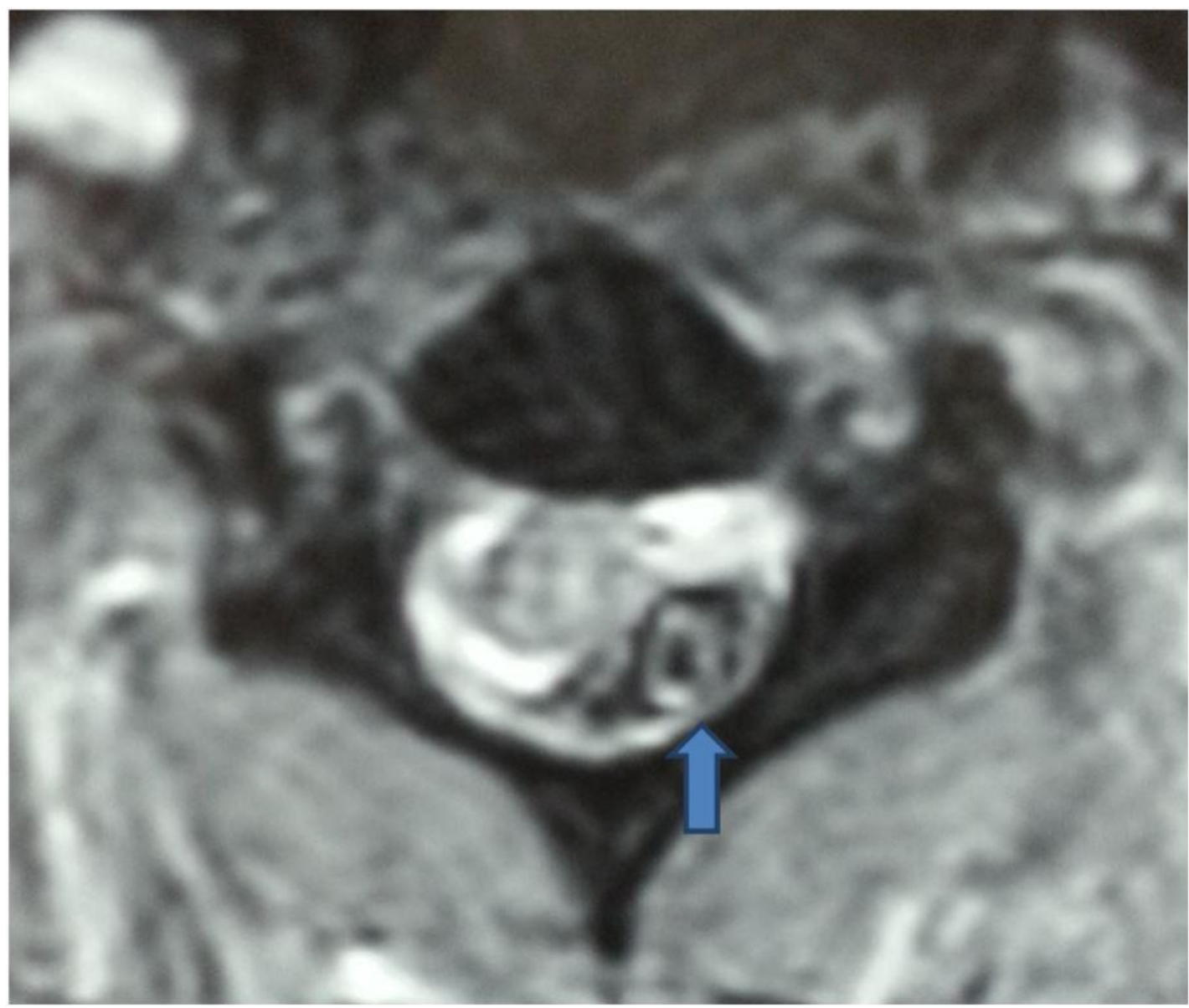

Figure 2. MRI (gradient echo) showing cervical EDH posterolateral to cord.

about $8 \mathrm{~km}$. He felt numbness in both the legs. He took analgesics. Next morning when he got up, he was unable to move his legs and was unable to pass urine. He was seen by a neuro-physician and clinical evaluation revealed sensory impairment below D-6 level with flaccid paralysis of both lower limbs. His bladder was distended. His MRI was performed in emergency and it revealed a dorsal spinal extradural hematoma.

He was operated by noon whereby a dorsal D2 to D5 laminectomy and evacuation of hematoma was done. Six years after surgery he remains paraplegic with stiffness of the legs. MRI shows myelomalacia (Figure 5).

\section{Case 4}

An 18 year old high school student fell on his back while playing football. He could get up from the ground but with pain in the back of the neck. After initial first aid, he went home and had to take analgesics. But his pain persisted. Next morning he woke up with weakness of both the legs. $\mathrm{He}$ was unable to walk and was unable to pass urine. Clinically he was unable to move his neck. His bladder was distended. He had weakness of both upper limbs with sensory impairment below the level of Cervical-6. MRI revealed large posteriorly located EDH. Emergency surgery consisting of laminectomy and removal of the $\mathrm{EDH}$ was done. Six months later he recovered completely. No subsequent follow up was available.

\section{Case 5}

A female aged 45 years was admitted to a peripheral hospital. She was a known hypertensive and diabetic patient. She had a fall from the stairs that very same morning. Her only complaint was weakness of both legs after the fall. Her MRI revealed a dorso-lumbar EDH posteriorly located (Figures 6 and 7). Surgical evacuation of the clot was done in emergency. She recovered completely when seen 8 months following surgery.

\section{DISCUSSION}

A SEH is a rare but significant neurological condition (Steinmetz et al., 2003; Henry et al., 2012; Solero et al., 1980). It accounts for less than one percent of all epidural 


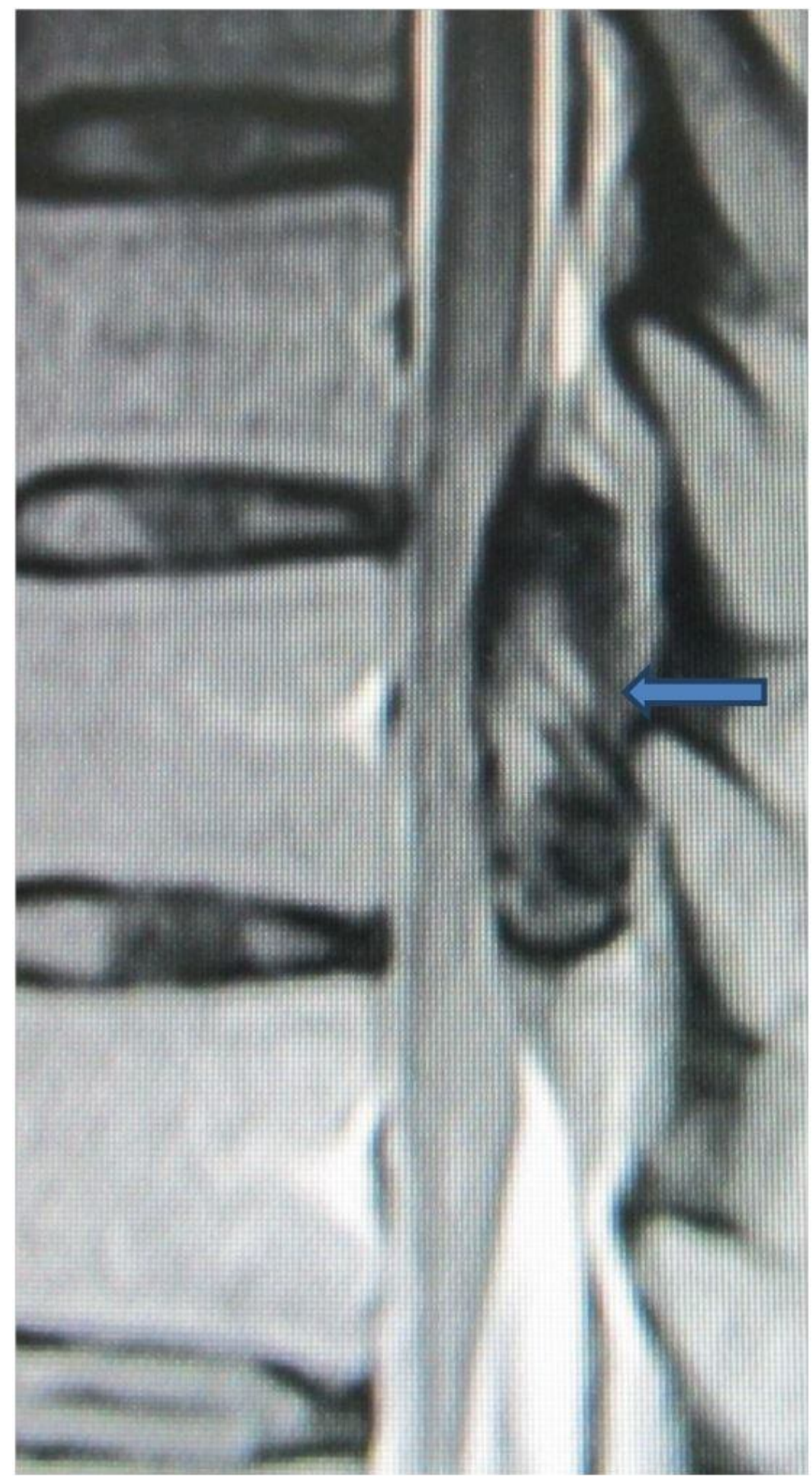

Figure 3. MRI T2 Image showing EDH with bright and dark signals and cord edema.

compressive pathologies (Wang et al., 2011). Trauma and iatrogenic causes seem to be the most important and common causes reported against a setting of certain precipitating factors such as coagulopathies including Hemophilia B and factor XI deficiency (Steinmetz et al.,
2003), arterio-venous malformation (Solero et al., 1980; Wang et al., 2011), anticoagulant therapy (Solero et al., 1980; Wang et al., 2011) and therapeutic thrombolysis for acute $\mathrm{MI}$ and following prolong Valsalva Maneuvers (Henry et al., 2012). It is also a rare occurrence during 


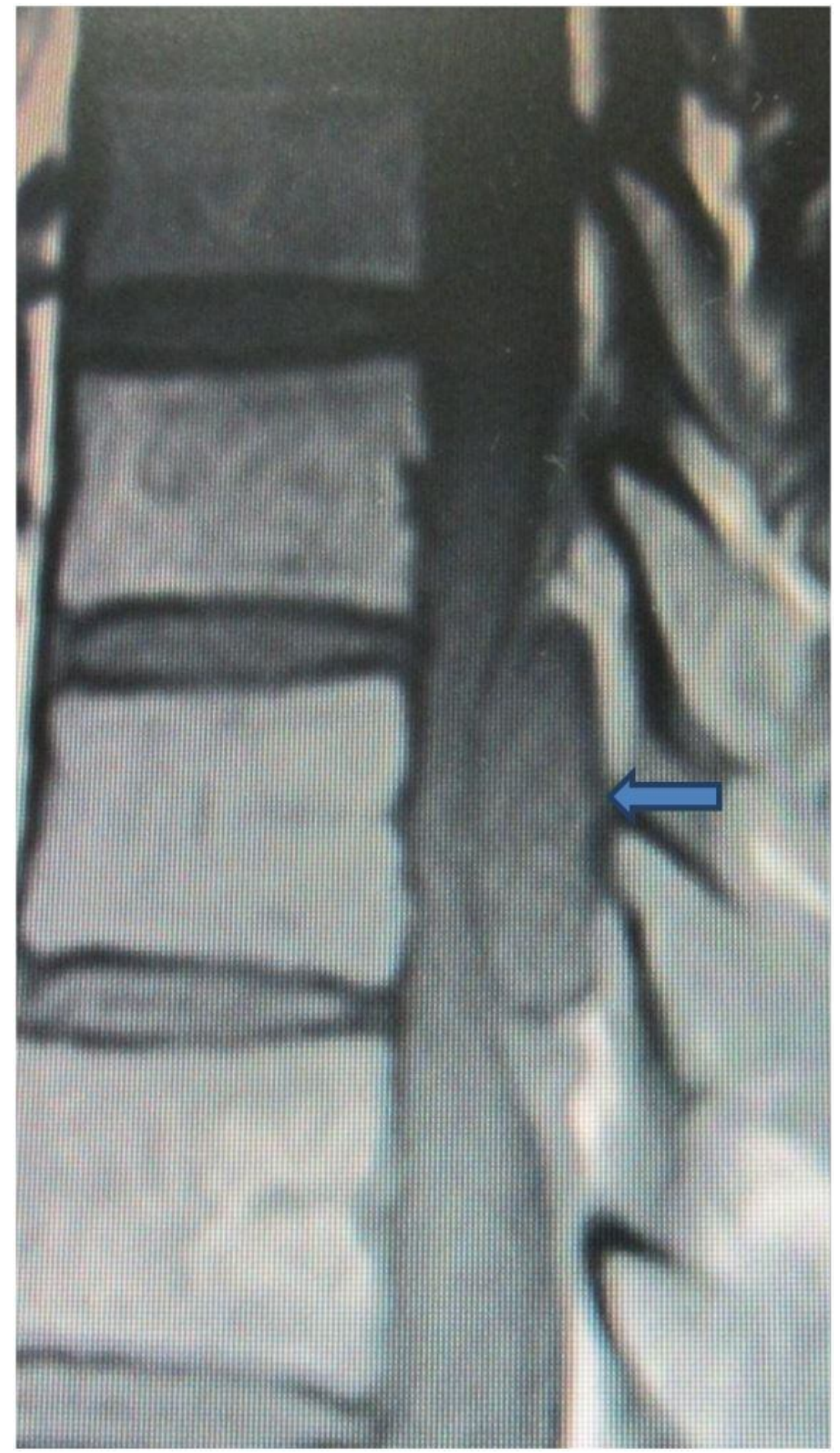

Figure 4. MRI PD image showing EDH isointense to cord.

pregnancy with only less than ten cases reported in literature (Bose et al., 2007; Krishnan and Kartikueyan, 2014). Statistically traumatic cases account for a small percentage of all SEH (Liu et al., 2008).Common sites for traumatic SEH as seen in our cases too are the cervicothoracic region and thoraco-lumbar region.
There have been many disputes regarding the origin of these hematomas. Research shows that SEH arises from epidural venous plexus in the spinal epidural space because it lacks venous valves and undulating pressure from the thoracic and abdominal cavities can impact it directly (Liu et al., 2008; Guzel et al., 2007; Riaz et al., 


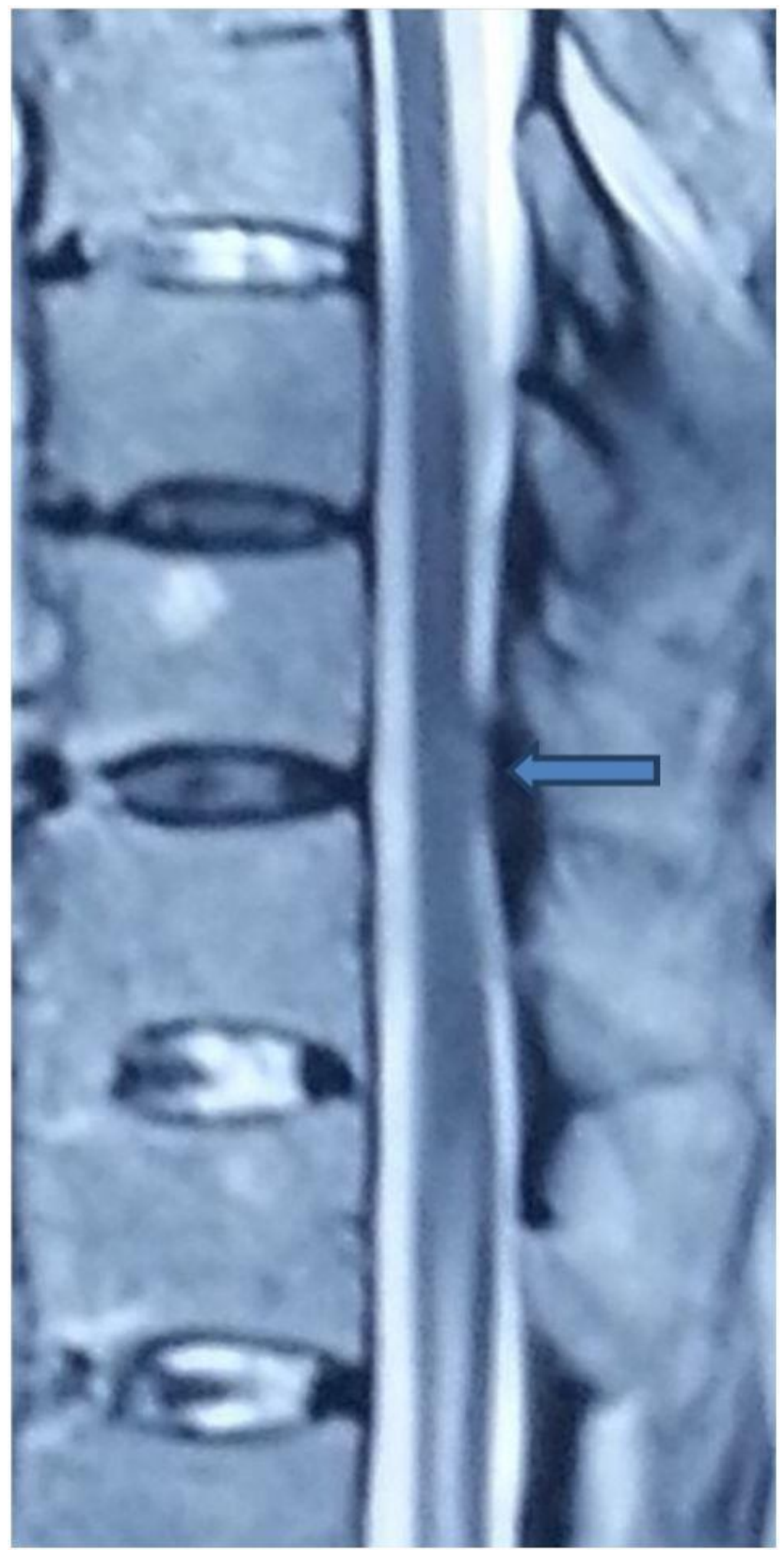

Figure 5. MRI T2 image showing posterior compression and cord signals.

2007). Several authors have proposed the spinal epidural arteries as a source of haemorrhage (Solheim et al., 2007). This could be because the pressure from the arterial bleeding (caused by trauma as in our cases) compresses the spinal cord as the intra-thecal pressure is higher than the venous pressure (Guzel et al., 2007; 


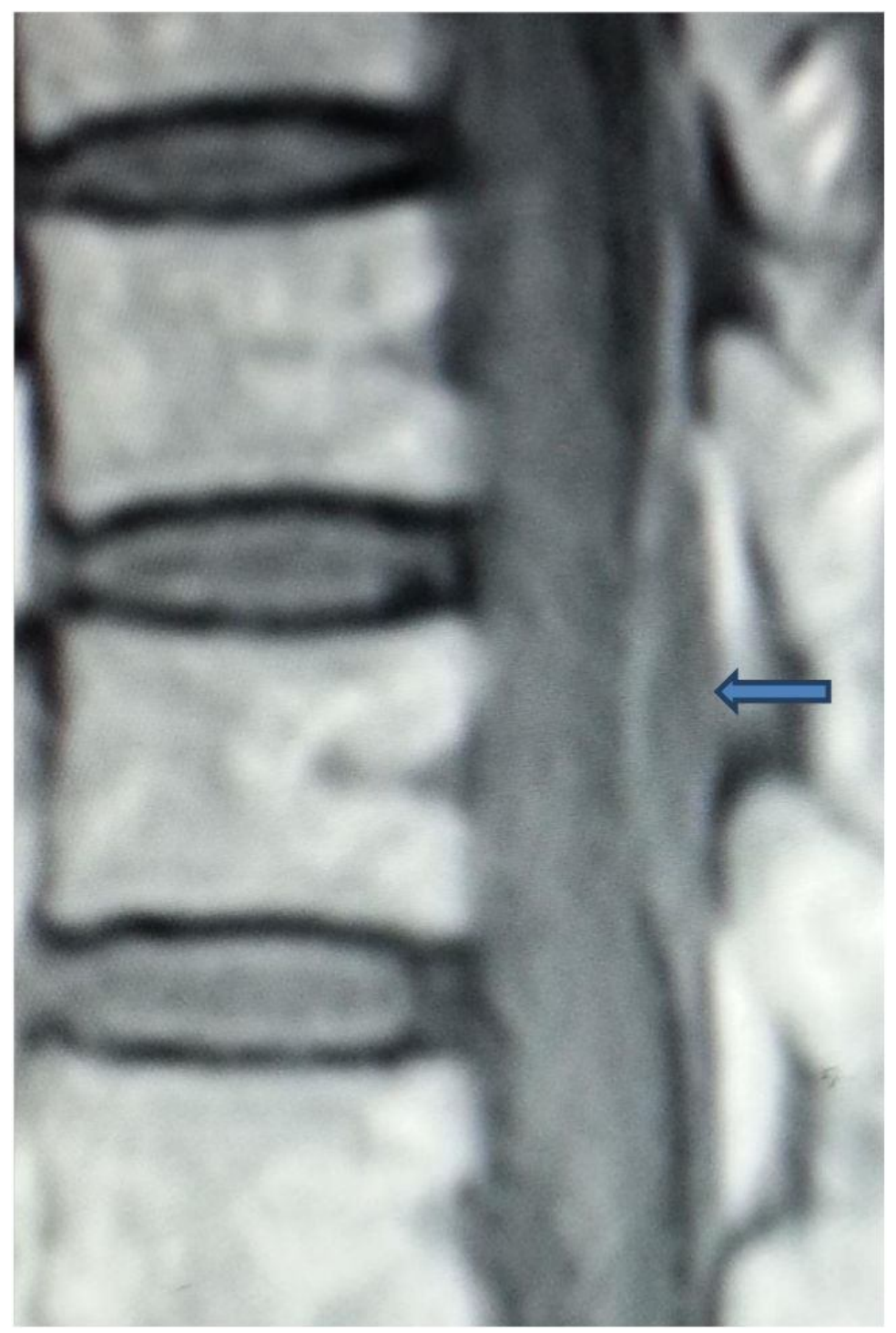

Figure 6. MRI PD image showing posteriorly located EDH and cord compression.

Riaz et al., 2007).

The usual clinical presentation for traumatic spinal epidural hematoma as seen in all our cases is dull aching local pain following trauma over the affected region of spine that gradually increases with time and progresses towards paraparesis or quadriparesis, depending on the level of the lesion and nerve root involved (Hangping et al., 2007).

Currently, MRI is considered as the first choice of investigationand is considered gold standard in the diagnosis of SEH (Matsumura et al., 2007; Song and Lee, 2005). Typically a biconvex hematoma is seen in the epidural space with well defined borders tapering superiorly and inferiorly (Fujiwara et al., 2005). A CTscan may be obtained if MRI is not available (Riaz et al., 2007). However, spinal cord injury without any radiological abnormality is very well documented (Pang,
2004) (as seen in our case 1 and 2).

Early surgical intervention is the choice of treatment for traumatic SEH. The procedure includes decompressive laminectomy with removal of the hematoma that may or may not be followed by a laminoplasty (Wang et al., 2011; Szkup and Stoneham, 2004). In cases with incomplete neurological deficit, early surgical intervention should be undertaken preferably within $48 \mathrm{~h}$ of onset of initial symptoms (Liu et al., 2008). If initial neurological deficits are complete, operation should be performed within $36 \mathrm{~h}$ (Liu et al., 2008). Literature shows that conservative treatment is also employed but only when neurological deficits improve in the early phase or with the coexistence of a coagulopathy (Tailor et al., 2006). Multilevel traumatic SEH may be difficult to treat operatively in patients with coagulopathy (Ziyal et al., 2003) and these patients should be therefore protected 
from significant risk of a surgical intervention.

\section{Conclusion}

To conclude, Spinal Epidural Hematoma must be kept in mind and ruled out in any patient who has sustained a trauma over the spinal region. This paper has reported five such cases of traumatic SEH encountered and studied over a period of nine years. For the treatment of SEH of any etiology, surgical intervention should be considered as soon as possible unless the neurologic deficit takes a favorable turn in the early phase or if the patient has a coagulopathy. An emergency surgical evacuation of the clot with decompression of the cord is associated with good functional recovery.

These cases show that Traumatic SEH may not truly be a rare entity and must be taken into consideration in a background of trauma. So is it possible that most cases of Traumatic SEH are overlooked and considered as Spontaneous Spinal Epidural Hematoma? In any case, a detailed history and awareness among specialists along with support from diagnostic tools seems to be the cardinal answer to this question.

\section{REFERENCES}

Bose S, Ali Z, Rath GP, Prabhakar H, 2007. Spontaneous spinal epidural hematoma: a rare cause of quadriplegia in the post-partum period. Br J Anaesth, 99: 855-857.

Cha JR, Park KB, Ko SH, 2011. Post-traumatic Lumbar Epidural Hematoma with neurology: Report of 1 case. Asian Spine J, 5(2): 130-132.

Fujiwara H, Oki K, Momoshima S, Kuribayashi S, 2005. Propeller diffusion-weighted magnetic resonance imaging of acute spinal epidural hematoma. Acta Radiol, 46: 539-542.

Guzel A, Simsek O, Karasalihoglu S, Kucukugurluoglu Y, Acunas B, Tosun A, Cakir B, 2007. Spontaneous spinal epidural hematoma after seizure: a case report. Clin Pediatr (Phila), 46: 263-265.

Hangping Y, Shunwu F, Huilin Y, Tiansi T, Feng Z, Xing Z, 2007. Early diagnosis and treatment of acute or subacute spinal epidural hematoma. Chin Med J, 120: 1303-1308.

Henry JB, Messerer M, Thomas V, Diabira S, Morandi X, Hamlat A, 2012. Nontraumatic spinal epidural hematoma during pregnancy: Diagnosis and management concerns. Spinal Cord, 50: 655-690.

Krishnan P, Kartikueyan R, 2014. Spontaneous spinal epidural hematoma: A rare cause of paraplegia in pregnancy. Neurol India, 62: 205-207.

Lefranc F, David P, Brotchi J, De Witte O, 1999. Traumatic epidural hematoma of the cervical spine: Magnetic resonance imaging diagnosis and spontaneous resolution: Case report. Neurosurgery, 44: 408-410.

Liu Z, Jiao Q, Xu J, Wang X, Li S, You C, 2008. Spontaneous spinal epidural hematoma: analysis of 23 cases.Surg Neurol, 69: 253-260.

Matsumura A, Namikawa T, Hashimoto R, Okamoto T, Yanagida I, Hoshi M, Noguchi K, Takami M, 2007. Clinical management for spontaneous epidural hematoma: diagnosis and treatment. Spine J, 8: 534-537.

Pang D, 2004. Spinal cord injury without radiographic abnormality in children, 2 decades later. Neurosurgery, 55(6): 1325-1342.

Riaz S, Jiang H, Fox R, Lavoie M, Mahmood JK, 2007. Spontaneous spinal epidural hematoma causing Brown-Sequard syndrome: case report and review of literature. J Emerg Med, 33: 241-244.
Solero CL, Fornari M, Savoiardo M, 1980. Spontaneous spinal epidural hematoma arising from ruptured vascular malformation. Case report. Acta Neurochir (Wein), 53: 169-174.

Solheim O, Jorgensen JV, Nygaard OP, 2007. Lumbar epidural hematoma after chiropractic manipulation for lower back pain: Case Report. Neurosurgery, 61: E170-E171.

Song KJ, Lee KB, 2005. The poor outcome of the delayed diagnosis of acute spontaneous spinal epidural hematoma: two case report. J Korean Med Sci, 20: 331-334.

Steinmetz MP, Kalfas IH, Willis B, Chalavi A, Harlan RC, 2003. Successful surgical management of a case of spontaneous epidural hematoma of the spine during pregnancy. Spine J, 3: 539-542.

Szkup P, Stoneham G, 2004. Case report: Spontaneous spinal epidural hematoma during pregnancy: Case report and review of the literarure. Br J Radiol, 77: 881-884.

Tailor J, Dunn IF, Smith E, 2006. Conservative treatment of spontaneous spinal epidural hematoma associated with oral anticoagulant therapy in a child. Childs Nerv Syst, 22: 1643-1645.

Wang P, Xin XT, Lan H, Chen C, Liu B, 2011. Spontaneous cervical epidural hematoma during pregnancy: Case report and literature review. Eur Spine J, 20: S176-9.

Ziyal IM, Aydin S, Inci S, Sahn A, Ozagen T, 2003. Multilevel acute spinal epidural hematoma in a patient with chronis renal failure-case repor. Neurol Med Chir (Tokyo), 43: 409-412.
Citation: Prusty L, Prusty GK, 2017. Traumatic spinal epidural hematoma: A case review. Int Res J Med Med Sci, 5(1): 1-8. 